Brit. J. industr. Med., 1952, 9, 221.

\title{
THE EFFECT OF PSYCHOLOGICAL HANDICAP IN TWO FACTORY GROUPS
}

\author{
BY \\ MORRIS MARKOWE and L. E. D. BARBER \\ From the Medical Research Council Unit for Research in Occupational Adaptation
}

(RECEIVED FOR PUBLICATION MARCH 25, 1951)

This paper describes one of a series of investigations to determine the effect of psychological handicap on productivity and occupational adjustment. Two independent groups of apparently healthy conveyor assembly workers were studied. Each member of the group was examined medically and psychologically and these findings were considered in relation to the productivity and absenteeism of the two groups.

\section{The Groups}

The groups were in a factory making lead accumulators. The factory has been established for over 50 years in an industrial area near Manchester, and is the largest manufacturing unit in a coordinated group of firms. The labour is drawn from a community which has a wide range of acquired techniques and a long industrial tradition.

The groups were responsible for the final assembly of batteries; each contained some 28 men and women and a charge-hand. The charge-hands were responsible to the same foreman.

The groups cannot be considered to be in any sense a random collection of people as they were formed by a continuous process of selection ; indeed, the selection may have resulted in a concentration of men and women with broadly similar characteristics.

\section{Methods of Study}

The investigation was made during three periods in 1949. During the first period, from January to March, preliminary assessments of productivity were made before the groups were aware of the project.

During the second period, from March to June, workers were interviewed and examined. On Wednesday of each week batteries of the same type were allotted to the groups for assembly to compare their output as accurately as possible.

In the third period, from October to December, the charge-hands were transposed in order to measure the effect of the changed supervision on productivity and absenteeism.

More than 30 different types of battery were being assembled. This involved the groups in frequent changes in working methods, and made it necessary to use a performance index as a measure of output. Group working in the factory has been valued by accepted "work-study" techniques. Earnings are calculated for each day on the basis of a performance index which is the result of dividing "work-minutes" by actual clock minutes and multiplying by 100 . "Work-minutes" are the product of the number of pieces completed and the standard time allowed for each piece. Time allowances are added for delays in production due to changing types of work, lack of materials, mechanical breakdowns, washing, preparing the work place, time sheet recording, etc. In this enquiry a performance index without any of these additions was used to measure the output of those working on conveyors A and B (Group A and Group B). An actual count of comparable units was not found to be practicable.

A record of each worker's life history was made, and included details of habits, previous health, work experience, recent social circumstances, and health; their attitudes, moods, and sociability were also assessed. Special attention was paid to persistence in the face of difficulties and perseverance. Interests and preferences were noted, as well as tendencies to emotional instability, maturity, and timidity. Physical examination included the recording of anthropometric data (Cureton, 1947), tests of manual strength, cardiovascular efficiency (Schneider and Karpovich, 1948), haemoglobin index, and where necessary, a clinical examination. A small battery of psychological tests was also used (see Appendix for details). Interview time and examination were kept to a minimum and the 
confidential nature of the enquiry stressed at every opportunity. The foreman was asked to rate each worker on 3-point scales. Ratings were made by the investigator on a 4-point scale for physical and mental health, and 3-point scales for certain personality features such as emotional instability, maturity, persistence, timidity, anxiety, and obsessional traits. Records of all forms of absenteeism were obtained from the foreman of the department for the periods January 1 to June 30, 1949.

\section{The Findings}

There were few significant differences between the groups for the various health indices used (Table 1). The more important ones will be discussed below.

TABLE 1

MEAN SCORES OF TEST RESULTS

\begin{tabular}{|c|c|c|c|c|c|}
\hline & & \multicolumn{2}{|c|}{ Males } & \multicolumn{2}{|c|}{ Females } \\
\hline & & A & B & A & B \\
\hline $\begin{array}{l}\text { Schneider Index } \\
\text { Standard deviation }\end{array}$ & . & $\begin{array}{r}13 \cdot 19 \\
2 \cdot 04\end{array}$ & $\begin{array}{r}14 \cdot 33 \\
4 \cdot 15\end{array}$ & $\begin{array}{r}12 \cdot 15 \\
3 \cdot 56\end{array}$ & $\begin{array}{r}12 \cdot 67 \\
2 \cdot 70\end{array}$ \\
\hline Persistence Test . . & : & $32 \cdot 88$ & 29.93 & $20 \cdot 85$ & $20 \cdot 83$ \\
\hline Standard deviation & & $9 \cdot 80$ & $14 \cdot 37$ & $7 \cdot 54$ & 9.92 \\
\hline $\begin{array}{l}\text { Maudsley Questionnaire } \\
\text { Standard deviation }\end{array}$ & $\cdots$ & $\begin{array}{l}8 \cdot 27 \\
6 \cdot 15\end{array}$ & $\begin{array}{l}7 \cdot 27 \\
5 \cdot 8 \pi\end{array}$ & $\begin{array}{l}6 \cdot 92 \\
4 \cdot 84\end{array}$ & $\begin{array}{l}7 \cdot 83 \\
4 \cdot 62\end{array}$ \\
\hline Thurstone Reasoning Test & $\therefore$ & 7.67 & $9 \cdot 60$ & $\begin{array}{l}4 \\
4 \cdot 69\end{array}$ & 4.67 \\
\hline Standard deviation & $\ldots$ & $5 \cdot 07$ & $6 \cdot 08$ & $3 \cdot 27$ & 3.25 \\
\hline Word Connection Test & .. & $11 \cdot 80$ & 11.93 & 13.69 & 13.42 \\
\hline Standard deviation & & $3 \cdot 85$ & $6 \cdot 49$ & $7 \cdot 39$ & 5.01 \\
\hline
\end{tabular}

Psychological Test Battery.-The mean intelligence score (on Thurstone's Reasoning Test) for Group B males was slightly greater than for Group A; the female scores in both groups were the same. Crown's Word Connection Test showed no suggestive differences between the groups, although females had a higher (abnormal) mean score than the males. In the Sentence Completion Test (a form of projective technique) the majority of the responses were extremely limited but were helpful in understanding particular attitudes or needs. The Maudsley Medical Questionnaire scores showed no significant differences. Finger dexterity scores for assembly and dis-assembly showed the groups to be remarkably alike ; thus, these tests did not indicate any obvious difference in the neurotic tendencies of the groups.

Physical Data.-Both groups showed a tendency to ectomorphy, that is, slender body build on Sheldon's scale (Sheldon, 1940), with a predominance in Group B due mainly to the males; this was calculated by means of the Reciprocal Ponderal Index from heights and weights. This index (height/ cube root of weight) provided a single indicator of an individual's position on the ectomorphy-endomorphy scale, without having to resort to the special photographic technique of somatometry, obviously inapplicable in industry. Cardiovascular efficiency was slightly lower in Group A than in Group B, from which a greater tendency towards emotional instability was suggested since no obvious cardiovascular defects were found in either group (McFarland and Huddleson, 1936). On the measure of persistence, Group A males were slightly better than those in Group B.

Health and Personality Trait Assessments.Group B contained more individuals within the normal range in both physical and mental health, whereas Group A included two cases of definite neurosis. Tests of significance were applied to the distribution of traits between the groups. The only important differences were that Group A showed more emotional instability and timidity (especially among the women) and greater anxiety, but only the latter was significant at the $5 \%$ level, whereas Group B was more mature, especially its men ; this difference was significant at the $5 \%$ level.

Sociability.-The groups were constituted in the previous January (approximately three months before the interviews began), so that the experience of working as a group, as well as past friendships (in other parts of the shop and works) must be taken into consideration. Table 2 shows the friendships within and between the groups. Thus in Group A some 10 internal social bonds were found, as contrasted with Group B's 17. We may conclude that Group B was friendlier and more closely knit than Group A. This is a factual matter and quite independent of any hypothetical observations on group unity or morale.

TABLE 2

FRIENDSHIPS WITHIN AND BETWEEN GROUPS

\begin{tabular}{|c|c|c|c|}
\hline & $\begin{array}{l}\text { Friendships } \\
\text { in Group A }\end{array}$ & $\begin{array}{l}\text { Friendships } \\
\text { in Group B }\end{array}$ & Total \\
\hline Group $A\left\{\begin{array}{l}15 \text { males } \\
13 \text { females . }\end{array}\right.$. & $\begin{array}{l}6 \\
4\end{array}$ & $\begin{array}{l}4 \\
3\end{array}$ & $\begin{array}{r}10 \\
7\end{array}$ \\
\hline Totals $\quad \ldots$ & 10 & 7 & 17 \\
\hline Group $B\left\{\begin{array}{l}15 \text { males } \\
13 \text { females : }\end{array}\right.$ & $\begin{array}{l}8 \\
9\end{array}$ & $\begin{array}{l}2 \\
4\end{array}$ & $\begin{array}{l}10 \\
13\end{array}$ \\
\hline Totals & 17 & 6 & 23 \\
\hline
\end{tabular}

Socio-Economic Data.-The only significant differences were in the categories of age and absenteeism.

Age.-The mean age for males in Group B was some five years greater than for Group A, thus implying that Group B had greater industrial experience. 
TABLE 3

ABSENTEEISM * OF WORKERS ON CONVEYOR BELTS A AND B BETWEEN JANUARY 1 AND JUNE 30, 1949

\begin{tabular}{|c|c|c|c|c|c|c|c|c|c|c|}
\hline \multirow{2}{*}{\multicolumn{5}{|c|}{ Group }} & \multicolumn{2}{|c|}{ Sickness } & \multicolumn{2}{|c|}{ With and Without Permission } & \multicolumn{2}{|c|}{ All Reasons } \\
\hline & & & & & Days & Average Days & Days & Average Days & Days & Average Days \\
\hline$A: \begin{array}{l}15 \text { males } \\
13 \text { females } \\
\text { Totals } 28\end{array}$ & $\begin{array}{l}\cdots \\
\cdots\end{array}$ & $\begin{array}{l}\cdots \\
\cdots\end{array}$ & $\begin{array}{l}\cdots \\
\cdots \\
\cdots\end{array}$ & $\begin{array}{l}\cdots \\
\cdots\end{array}$ & $\begin{array}{l}6 \\
3 \\
9\end{array}$ & $\begin{array}{l}0 \cdot 4 \\
0 \cdot 2 \\
0 \cdot 3\end{array}$ & $\begin{array}{r}7 \\
5 \\
12\end{array}$ & $\begin{array}{l}0 \cdot 5 \\
0 \cdot 4 \\
0 \cdot 4\end{array}$ & $\begin{array}{r}13 \\
8 \\
21\end{array}$ & $\begin{array}{l}0.9 \\
0 \cdot 6 \\
0 \cdot 8\end{array}$ \\
\hline B $\left\{\begin{array}{l}15 \text { males } \\
13 \text { females } \\
\text { Totals } 28\end{array}\right.$ & $\begin{array}{l}\cdots \\
\cdots\end{array}$ & $\begin{array}{l}. \\
\cdots\end{array}$ & $\begin{array}{l}\cdots \\
\cdots\end{array}$ & $\begin{array}{l}\cdots \\
\cdots\end{array}$ & $\begin{array}{r}38 \\
7 \\
45\end{array}$ & $\begin{array}{l}2.5 \\
0.5 \\
1.6\end{array}$ & $\begin{array}{r}9 \\
6 \\
15\end{array}$ & $\begin{array}{l}0.6 \\
0 \cdot 5 \\
0 \cdot 5\end{array}$ & $\begin{array}{l}47 \\
13 \\
60\end{array}$ & $\begin{array}{l}3 \cdot 1 \\
1 \cdot 0 \\
2 \cdot 1\end{array}$ \\
\hline
\end{tabular}

* Excluding annual leave and public holidays.

Absenteeism.-Table 3 gives interesting data on absenteeism, but is inconclusive because of the small numbers in the groups. Analysis indicated a surprising difference from accepted absentee behaviour. Males were responsible for $62 \%$ and $78 \%$ of all time lost on the conveyor belts for all reasons. Absenteeism, which was evenly distributed among the groups, was about three times higher in the more productive conveyor group B than in A. It has been generally held that absenteeism is related to a lower standard of occupational adjustment ; in the present enquiry the contrary is indicated by all other measures of industrial effectiveness.

Foreman's Ratings. - The foreman's ratings for industrial effectiveness showed no difference between the groups.

The foreman was asked to select what in his view would be the most effective group of 28 persons from the total of 56 . The mean scores from test results of the selected group and the rest were approximately the same but the out- standing difference was the narrow scatter in the selected team. It was as if they conformed far more closely to the hypothetically efficient worker in respect of their test performance, while any marked variants from this mean-in either direction-were omitted.

Output.-The output differences of the two groups based on the performance index are given in Fig. 1 and Table 4. (1) Group A may be regarded as being slightly less productive than Group B in the first period before being exposed to the unusual stimulation of this study. (2) The less productive group A was relatively more affected by the investi-

TABLE 4

THE MEAN OUTPUT OF THE TWO GROUPS FOR THE THREE PERIODS STUDIED

\begin{tabular}{|c|c|c|c|c|}
\hline Periods & & I & II & III \\
\hline Group A $\left\{\begin{array}{l}\text { Mean. . } \\
\text { S.D. . }\end{array}\right.$ & $\begin{array}{l}\cdots \\
\cdots\end{array}$ & $\begin{array}{r}177 \\
1.63\end{array}$ & $\begin{array}{l}188 \\
1 \cdot 80\end{array}$ & $\begin{array}{r}192 \\
0.85\end{array}$ \\
\hline Group B $\left\{\begin{array}{l}\text { Mean. . } \\
\text { S.D. . . }\end{array}\right.$ & $\begin{array}{l}\cdots \\
\cdots\end{array}$ & $\begin{array}{r}185 \\
1 \cdot 08\end{array}$ & $\begin{array}{r}187 \\
1 \cdot 25\end{array}$ & $\begin{array}{r}196 \\
1 \cdot 10\end{array}$ \\
\hline
\end{tabular}

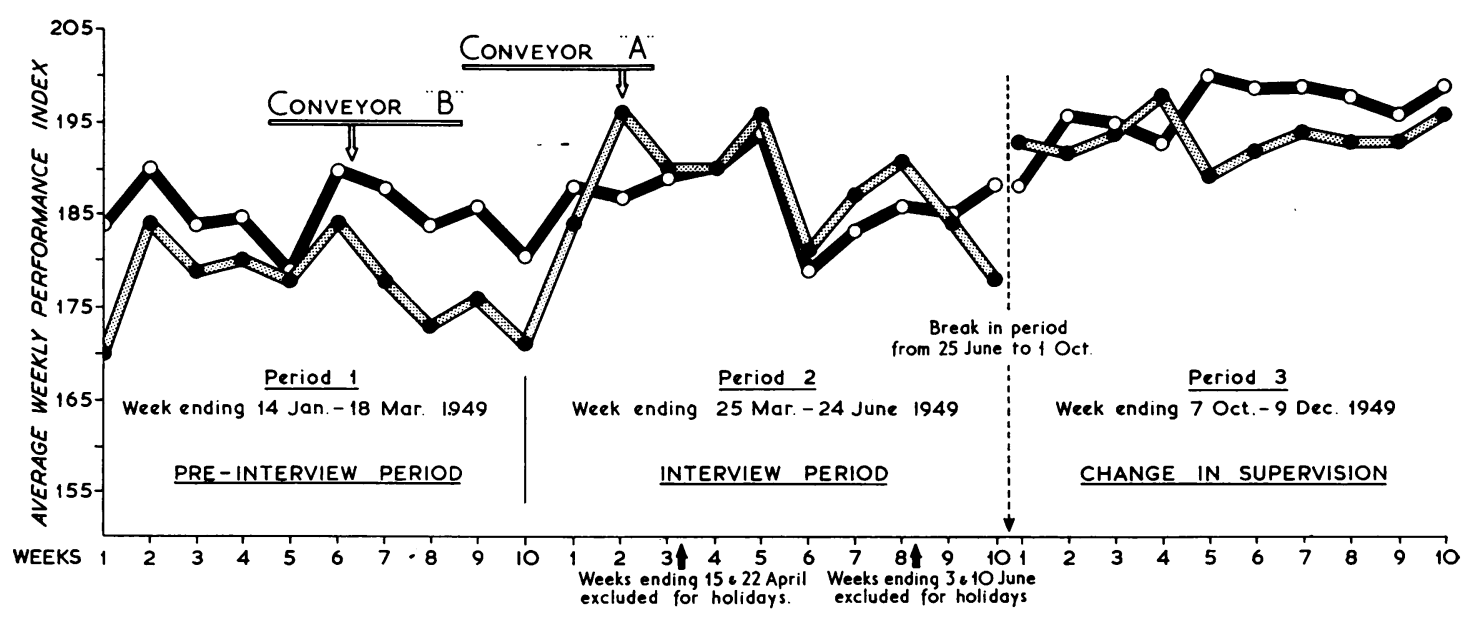

FIo. 1 
gation than was Group B. (3) In the third period both groups increased their output but Group B relatively more than Group A. (4) The question must remain open as to whether the improvement in the performance index of both groups, as it appears in a comparison between Periods I and III, is attributable to the effects of being investigated, the change-over of the charge-hands, a combination of both these elements, some unknown alteration in the internal basis of the performance index, which careful and prolonged enquiry failed to elicit, improvement due to practice, or combinations of these.

In the second period when daily interviews, personal contacts, research interest, and special production days were instituted, we find a suggestive rise in effectiveness of both groups. Group A, the less effective, was relatively more influenced by these factors. How far such change can be ascribed to stimulation due to unusual research activity cannot be estimated. Close examination of all the normal factors affecting output shows no specific changes and therefore explanation along the lines of the Hawthorne* findings could be acceptable. The differences in weekly average performance indices as shown in Fig. 1 appear to be consistently reduced during the second period.

For the third period, we have attempted to investigate the effects of a change of supervision on the groups. Sufficient time elapsed between the second and third periods to allow the groups to settle down after this change, and the upheavals caused by holidays. There was an appreciable higher level of the performance index of both groups, and, further, the difference between the average performance indices was reduced compared with the first period. Close examination of industrial and economic factors has revealed no forces adequate to account for these changes; hence it appears that the transposition of the supervisors may have altered the psychological and social milieu sufficiently to affect industrial effectiveness.

\section{Discussion}

The complexity of physical, mental, and social health defies neat scientific measurement. This is particularly obvious when one attempts to treat the occupational health of a worker as an entity divorced from social and domestic affiliations. Our main purpose has always been to study the biological

* These, based on the now classical social and psychological studies at the Hawthorne plant of the Western Electric Company near Chicago, are that close investigation of any group will usually affect its behaviour and hence its industrial performance, usually for the better (Mayo, 1933; Roethlisberger and Dickson, 1939; Whitehead, 1938). adaptation of our population in the work situation but always against the total domestic, social, and economic background.

Output in Relation to Health.-Our measures of group health indicate that physically Group B contained more individuals within the limits of normality than did Group A. On the mental side, there were two cases of definite neurosis in Group A but none in Group B ; there were few other significant differences in their mental health. However, analysis of personality trait ratings showed that Group A possessed more unstable, timid, and anxious females than Group B, and its workers were emotionally less mature. Group B thus appeared to be the more healthy group mentally, and showed more stability and maturity than Group A. Dynamically and socially, Group B was also considered to be more effective than Group A as shown by measures of friendliness within and between the groups. These findings would appear to support the widely accepted view that industrial effectiveness is related to the health of the group.

Output in Relation to Key Workers.-It was found that Group A's leading hand was stronger physically and enjoyed excellent health, whereas Group B's was only rated fair because he had emphysema. Psychologically the leading hand in Group B was more intelligent and showed greater finger dexterity, also the leading hand of Group A was somewhat more unstable than the leading hand of Group B. However, both were within normal limits in regard to their recent mental health, although neither was in the highest grade. The leading hand of Group B was more mature than his counterpart of Group A; the latter was found to be aggressive, with a tendency to moderate anxiety reactions. Both were highly conscientious. The leading hand of Group A was assertive and energetic, but anxious, preferring his family circle to a wider social sphere. The leading hand of Group B was an even-tempered, older man, of pyknic build, moderately assertive, sociable but somewhat handicapped by his emphysema.

Output in Relation to Charge-hands.-Both charge-hands were undoubtedly in excellent physical health. Mentally, the charge-hand of Group A was found to be suffering from a mild anxiety state over the illness of his family, and had enjoyed only a fair degree of health in the past; there was a family history of mild instability. The past and present health of the charge-hand of Group B was excellent. Personality traits showed much similarity, yet the charge-hand of Group A was 
emotionally of high lability, a lean, nervous and hard-pressed man tending to require the support of his superior in day-to-day problems. His counterpart in Group B was a bluff, pyknic, hasty autocrat, and entirely self-sufficient in his work-a-day supervision. These personality differences appear to be closely related to the industrial effectiveness of their respective groups and the changes consequent on transposing the charge-hands.

Although the differences in industrial performance of the two groups are small, these findings suggest that the health of the charge-hands and key workers and the general health of the groups, which may have been influenced by the key workers and chargehands, did influence industrial effectiveness.

It has been widely accepted that the inclusion of maladjusted and unstable individuals in a working group is likely to reduce its industrial effectiveness owing to various factors : absenteeism (Russell Fraser, 1947 ; Wyatt, 1945) ; unemployment and frequent job changes (Lewis, 1935); accidents (Selling, 1944 ; Adler, 1941) ; prolonged rehabilitation (Jones, 1948), monotony and boredom (Wyatt and Langdon, 1937), friction with superiors, equals, and inferiors (Tredgold, 1949); and poor quality and quantity of work owing to inability to concentrate (Gibeson, 1947). Observations have already shown some output differences which may be the effect of minor degrees of maladjustment and instability between the groups. But absenteeism does not conform to the general pattern in that the less effective (and less healthy) Group A showed considerably less absence than the more productive one B (Table 3). On the other hand the high group cohesion (as measured by intra-group friendships) was significantly related to higher productivity. It has been found elsewhere that pride in the work group is an extremely important factor both in the cohesion and morale of the group, and in its productivity (Katz, 1949; Mayo and Lombard, 1944). There are strong indications in this investigation that homogeneity of the group, even when of lower intelligence, may be more important for group effectiveness than heterogeneity, even where the latter may include outstanding workers. However, such exceptional individuals may compensate when in key positions by setting a higher pace.

This investigation has emphasized the difficulties of mental health research in factories, not only because of the lack of adequate methods of health and personality assessment at work, but also because of the no less difficult task of measuring variations in output.

\section{Summary}

The relations between the medical and psychological characteristics and the industrial effectiveness of two independent and parallel groups of male and female workers were investigated.

Both groups of workers were engaged in the final assembly of lead-acid accumulators; each was supervised by a male charge-hand responsible to the same foreman.

The study was concerned with the first, second, and fourth quarters of 1949.

There were certain significant differences in the output of the two groups during the study.

The group showing better mental health, stability, and maturity was industrially more effective.

The leading hand of the group which was industrially more effective was on the whole healthier and more stable than the leading hand of the less effective group.

The charge-hands of the two groups differed significantly in personality and health, the differences appearing to influence the output of their respective groups.

Contrary to expectation, the group which was less healthy and industrially less effective, had less absenteeism than the other group.

The healthier group showed higher group cohesion, as measured by friendships extending beyond the workshop.

The industrial effectiveness of the group appeared to be more dependent on the homogeneity than on the range of abilities of its members.

We wish to thank our colleague, Dr. Alastair Heron, who joined the research team after the completion of this work, for his special assistance in the statistical treatment of the production data. Throughout the research, the firm's industrial medical officer, Dr. D. Malcolm, assisted in every way, and his support helped considerably to increase the workers' confidence in the research nature of the work. Professor Aubrey Lewis, Hon. Director of the Unit, and Professor Ronald Lane, of the Department of Occupational Health of the University of Manchester, made themselves continuously available for consultation; their advice, encouragement, and criticism were of the greatest value. Lastly, the workers on the conveyor belts concerned not only actively cooperated in the research project while engaged on the belts, but also willingly endured the interview, and without their help this investigation would have been impossible.

\section{REFERENCES}

Adler, A. (1941). Amer. J. Psychiat., 98, 99.

Cureton, T. K. (1947). Physical Fitness Tests and Appraisal. New York. 
Fraser, R. (1947). Rep. industr. Hlth Res. Board, Lond., No. 90. Gibeson, L. G. (1947). Med. Clin. N. Amer. 26.

Jones, M. (1948). J. ment. Sci., 94, 392.

Katz, D. (1949). In Current Trends in Industrial Psychology, by Dennis, W., and others. Pittsburgh.

Lewis, A. (1935). Lancet, 2, 293.

Mayo, E. (1933). The Human Problems of an Industrial Civilisation. New York.

and Lombard, G. F. F. (1944). Business Research Studies, No. 32. Harvard University, Boston, Mass.

McFarland, R. A., and Huddleson, J. H. (1936). Amer. J. Psychiat., 93, 567 .
Roethlisberger, F. J., and Dickson, W. J. (1939). Management and the Worker. Cambridge, Mass.

Schneider, E. C., and Karpovich, P. V. (1948). Physiology of Muscular Activity, 3rd ed. Philadelphia.

Selling, L. S. (1944). Industr. Med., 13, 504.

Sheldon, W. H. (1940). Varieties of Body Build. New York.

Tredgold, R. F. (1949). Human Relations in Modern Industry. London.

Whitehead, T. N. (1938). The Industrial Worker. London.

Wyatt, S., and Langdon, J. N. (1937). Rep. industr. Hlth Res. Board, Lond., No. 77.

, (1945). Rep. Industr. Hlth Res. Board, Lond., No. 86.

\section{A P P E N D I X}

Pencil and Paper Tests.-Four tests were included in this group.

Thurstone's Reasoning Sub-Test. ${ }^{*}$-This was employed as a brief test in the cognitive sphere (instruction approximately four minutes; performance six minutes ; total 10 minutes). A " $\mathrm{g}$ " factor loading of 0.8 is reported for this test.

Crown's Word Connection Test.-This is a modified word association test; two possible associations are supplied for each of 50 words, one characteristic of normals, one of neurotics. This was employed to assist in the gross screening of neurotics (Crown, 1947).

Sentence Completion Test.-This was introduced as an alternative method to word association, and its even more restricted modification of word connexion. Words or short phrases were given for completion into sentences. A 20-question test was devised with some five stimulus phrases relevant to the industrial setting. A time limit of 20 minutes was set. Only qualitative aspects of the responses were afterwards considered. No attempt was made to score quantitatively (Rotter and Willerman, 1947).

Maudsley Medical Questionnaire.-The label " medical" was to reduce the suspicion of probing into mental difficulties. It contains some 40 questions bearing mainly on neurotic and hypochondriacal complaints, and on a few medical topics. Various items also deal with inferiority and lack of sociability.

U.S.E.S. Finger Dexterity Tests.-These cover parts $O$ and $P$ of the U.S.E.S. General Aptitude Test Battery (1947). Both " assembly" and "disassembly" were used and scores noted over 90 seconds and 60 seconds respectively. Primarily these measure the ability to move the fingers and manipulate small objects with the

\footnotetext{
* From Primary Mental Abilities, 1947.
}

fingers, rapidly or accurately. Secondarily, the scores are said to be inversely related to neuroticism (Eysenck, 1947).

Physiological.-Two physiological tests were employed to measure body sway and persistence.

Static Ataxia (Body Sway).--Significant correlations have been demonstrated between total sway when standing erect without visual aid and neuroticism. The maximum antero-posterior movement of the head was measured while the subject stood erect with the eyes closed over a period of 30 seconds.

Persistence (Mercury Column).-This endurance, or persistence, test is part of the Flack battery evolved in the measurement of flying efficiency and flying strain (Med. res. Counc., 1920). With nose clipped the subject expires deeply through the mouth and then, after a full inspiration, blows the column of mercury in a manometer steadily to a height of $40 \mathrm{~mm}$. and maintains it at that level for as long as possible without breathing. The time during which the mercury column is sustained is measured in seconds.

Social Aspects.-In the course of the interview workers were asked about their work-friendships; how far they were limited to the canteen, how far to their own group, how far they extended outside the works. An indication was thus obtained of the degree to which group or sub-group cohesion existed. While not as ambitious as the Moreno sociogram, this simple method provides a measure of the actual social bonds within the group, or of positive personal relations.

\section{REFERENCES}

Crown, S. (1947). J. Personality, 16, 198 Eysenck, H. J. (1947). “Dimensions of Personality." London. 